Mens

Revue d'histoire intellectuelle et culturelle

\title{
Joseph Yvon Thériault. Évangéline : contes d'Amérique, Montréal, Québec Amérique, 2013, 399 p.
}

\section{Jean Morency}

Volume 16, numéro 1, automne 2015

URI : https://id.erudit.org/iderudit/1038993ar

DOI : https://doi.org/10.7202/1038993ar

Aller au sommaire du numéro

Éditeur(s)

Centre de recherche en civilisation canadienne-française

ISSN

1492-8647 (imprimé)

1927-9299 (numérique)

Découvrir la revue

Citer ce compte rendu

Morency, J. (2015). Compte rendu de [Joseph Yvon Thériault. Évangéline : contes d’Amérique, Montréal, Québec Amérique, 2013, 399 p.] Mens, 16(1), 168-172. https://doi.org/10.7202/1038993ar d'utilisation que vous pouvez consulter en ligne.

https://apropos.erudit.org/fr/usagers/politique-dutilisation/ 
à première vue chez cet ancien fervent militant de l'Action libérale nationale; mais l'abbé Gravel finit par voir en lui un précieux rempart contre les forces de gauche. Enfin, après 1960, au moment même où le sentiment indépendantiste sort de la marginalité et commence à constituer une option viable, Gravel reste sur son quant-à-soi, ne voulant pas être associé à la teinte de gauche qui colore désormais la Cause.

Dumas présente patiemment les choix de l'abbé Gravel, sans se priver de les commenter, favorablement ou défavorablement selon les cas, mais sans se livrer non plus à des jugements faciles. L'attention soutenue aux divers contextes, le recours constant à des citations, l'éclairage occasionnel de l'historiographie, sans parler de la limpidité de la prose, tout cela concourt à faire revivre une personnalité oubliée. Avec cette étude, on comprend mieux désormais que les chemins de la droite d'idées aient connu des méandres, au gré des individualités et des circonstances, sans pour autant se caractériser par des contradictions ou des incohérences. L'abbé Gravel ne fut pas une figure de premier plan de notre histoire, et l'auteur ne le prétend nullement, mais les lecteurs sauront gré à Alexandre Dumas d'avoir pris la peine d'éclairer son cheminement.

- Xavier Gélinas Musée canadien de l'histoire

\section{Joseph Yvon Thériault. Évangéline : contes d'Amérique, Montréal, Québec Amérique, 2013, 399 p.}

Huit ans après avoir remis en question, dans Critique de l'américanité, les fondements idéologiques et épistémologiques d'un concept alors en vogue dans le champ des études québécoises, Joseph Yvon Thériault nous propose, dans ce nouvel essai, une lecture captivante d'un phénomène qui apparaît pourtant exemplaire de l'américanité, soit la contribution du poème de Henry Wadsworth Longfellow au processus ayant présidé à la construction de trois identités collectives distinctes : l'identité américaine (nationale), l'identité acadienne 
(nationalitaire) et l'identité cadienne de la Louisiane (ethnique). Tout se passe donc comme si, après avoir vilipendé les travers et les dérives de l'américanité, Thériault s'ingéniait à nous donner une illustration de ce que pourrait être l'usage réfléchi de ce paradigme critique, en retissant patiemment les fils de "l'histoire identitaire de l'Amérique » (p. 14).

L'hypothèse centrale défendue par Thériault dans son essai est que le poème de Longfellow a participé à la fondation et à l'élaboration de trois récits différents : le récit américain, le récit acadien et le récit cadien. Dans la première partie de son essai, intitulé « Évangéline l'Américaine ", selon moi la plus convaincante et la plus resserrée de l'ouvrage, Thériault schématise de façon remarquable le contexte entourant la création d'Évangéline. Si au départ l'identité américaine a été élaborée en fonction de l'esprit des Lumières, tout bascule avec l'avènement du romantisme au XIX ${ }^{\mathrm{e}}$ siècle, qui va s'activer à construire un récit national. Ce récit s'articulera dans un premier temps autour de l'épisode des pèlerins du Mayflower, épisode qui donne un caractère messianique à la fondation des États-Unis et justifie bientôt l'idée de destinée providentielle du pays (The Manifest Destiny) pour ensuite nourrir toute la mythologie de la Frontière, telle que définie par Frederic Jackson Turner. C'est dans cet état d'esprit que s'inscrit l'œuvre de Longfellow. Publié en 1847, le poème Évangéline s'inspire à la fois de la tradition allemande (usage de l'hexamètre propre au récit de fondation, action campée dans le décor de la forêt nordique, thème de la séparation des amants), des principes démocratiques américains et de la mythologie de la Frontière. Le génie de Longfellow a été d'intégrer la réalité française et catholique de l'Acadie des origines à l'histoire de l'émergence de la nation américaine, la déportation des Acadiens illustrant les affres de la situation coloniale et les abus du pouvoir britannique, et leur établissement en Louisiane la supériorité des principes démocratiques. La longue errance d'Évangéline dans l'Hinterland américain exprime pour sa part l'attrait ressenti par Longfellow et ses contemporains pour l'esprit de la Frontière et les grands espaces de l'Ouest. Évangéline constitue ainsi un grand récit 
fondateur qui a contribué à façonner l'identité américaine, d'où l'extraordinaire popularité du poème du vivant de Longfellow. Mais cette popularité, comme Thériault l'explique bien, va décliner rapidement par la suite, le récit américain se transformant pour s'accorder, au lendemain des grandes vagues d'immigration du début du $\mathrm{xx}^{\mathrm{e}}$ siècle, à l'expression d'une société de consentement et non plus de descendance. Cette transformation explique l'oubli dans lequel va tomber la figure d'Évangéline : fille du Mayflower et non d'Ellis Island, l'héroïne du poème de Longfellow va bientôt disparaittre des mémoires, du moins aux États-Unis.

Il en va tout autrement pour le deuxième avatar de la figure, Évangéline l'Acadienne, qui fait l'objet de la partie suivante de l'essai de Thériault. Cette deuxième partie, qui touche de façon encore plus directe aux préoccupations de l'auteur, qui est lui-même d'origine acadienne, brosse un portrait saisissant de l'évolution de l'identité acadienne depuis 1755. Au moment où la figure d'Évangéline est à l'apogée de sa gloire aux États-Unis, elle fait son apparition en Acadie, grâce à la traduction qu'en a faite le poète canadien Pamphile Le May. Selon Thériault, les Acadiens présents dans les provinces maritimes dans les décennies qui suivent le Grand Dérangement n'auraient gardé aucun souvenir ou presque des déportations, et encore moins de leur expulsion de Grand-Pré, pour la bonne raison que la très grande majorité de ceux et celles qui ont été déportés au loin ne sont jamais revenus dans la région qui les a vus naître, à l'exception des habitants de la Baie-Sainte-Marie, en Nouvelle-Écosse. Dépourvus de mémoire et d'identité collectives, les Acadiens des Maritimes auraient donc été dans l'impossibilité de construire leur propre récit, du moins jusqu'à la publication de La France aux colonies de Rameau de Saint-Père en 1859, qui met en forme le récit acadien à partir de la vision léguée par Longfellow. La traduction d'Évangéline par Pamphile Le May en 1865 et la publication, un an plus tard, du roman Jacques et Marie de Napoléon Bourassa viendront donner une touche canadienne au récit de Longfellow. Thériault décrit bien les transformations que la traduction libre de Le May fait subir au texte 
original et qui en modifient le dessein d'ensemble, par exemple en accentuant la cruauté des Anglais. Le roman de Bourassa participe du même mouvement de canadianisation, que viendra parachever la publication, en 1887, d'Un pèlerinage au pays d'Évangéline de l'abbé Henri-Raymond Casgrain. Les principaux acteurs de la Renaissance acadienne seront ainsi à même de construire le récit acadien autour d'une mémoire en quelque sorte inventée, celle de la déportation de 1755. Thériault retrace bien l'action décisive de ces penseurs de l'identité acadienne, qu'il s'agisse de l'abbé Marcel-François Richard, de Pascal Poirier, de Placide Gaudet, de Pierre-Amand Landry et consorts, qui appartiennent à la même génération et que Thériault appelle les enfants d'Évangéline, tant ils ont été marqués par la vision victimaire du poème de Longfellow et par l'épisode douloureux du Grand Dérangement. C'est cette tradition qui sera mise à mal à partir des années 1960 et 1970, notamment par les essayistes Jean-Paul Hautecœur et Michel Roy. Certains essaient alors de substituer à la figure imaginaire et passive d'Évangéline de nouvelles figures d'identification, considérées comme plus vraies, plus véridiques (Beausoleil Broussard et Louis Mailloux). Deux écrivains sont représentatifs de ce courant qui remet en question la figure d'Évangéline : Antonine Maillet et Herménégilde Chiasson. Thériault s'ingénie pourtant à montrer que ces deux auteurs font de l'« évangélisme » sans le vouloir. Cela dit, Thériault ne parvient pas tout à fait à nous convaincre, son analyse des œuvres de Maillet et de Chiasson restant assez superficielle.

La troisième partie nous entraîne sur les traces d'Évangéline en Louisiane, parachevant ainsi le trajet qui va d'une logique nationale (Évangéline l'Américaine) à une logique nationalitaire (Évangéline l'Acadienne) à une logique ethnique (Évangéline la Cadienne). Thériault décrit très bien comment la conception romantique de l'histoire des Acadiens héritée du poème de Longfellow a trouvé un terreau de choix en Louisiane, où l'établissement des Acadiens s'est fait dans le contexte d'une société neuve, ce qui a favorisé l'émergence d'une culture de type ethnique, centrée sur l'individu et sa famille. Là aussi la mémoire vivante de la déportation aurait rapidement 
disparu, avant d'être relayée par une mémoire d'emprunt tributaire du poème de Longfellow. En Louisiane comme en Acadie du Nord, les années 1960, 1970 et 1980 entraîneront de profonds bouleversements, et la figure d'Évangéline sera bientôt considérée comme du " fakelore ", c'est-à-dire comme une tradition mensongère destinée à gommer les traces de la culture populaire.

L'excellent essai de Joseph Yvon Thériault se clôt par un long épilogue, "Évangéline postmoderne », rédigé sur un ton plus personnel et en un sens plus éclaté. Prenant acte des nouvelles lectures de l'œuvre de Longfellow aux États-Unis, qui réhabilitent sa dimension cosmopolite, Thériault en profite pour interroger ce qu'il considère comme les dérives actuelles du discours identitaire acadien. Plusieurs passent à la trappe, depuis l'auteur de ces lignes jusqu'à l'écrivaine Georgette Leblanc, en passant par Herménégilde Chiasson et Serge Patrice Thibodeau. L'auteur se montre particulièrement critique face au Congrès mondial acadien, un événement tendant à exprimer qu' «il n'existe plus d'Acadie mais que des Acadiens » (p. 364), ce qui confine justement le peuple acadien dans la logique victimaire héritée de Longfellow. La boucle est ainsi bouclée : on n'échappe pas facilement à Évangéline, à moins de s'appeler Gabriel!

- Jean Morency

Département d'études françaises

Université de Moncton 